Michael Baurmann

\title{
The Golden Age of the Campfire: Should We Take Our Ancestors Seriously?*
}

\begin{abstract}
In his book The Ethical Project Philip Kitcher presents an 'analytical history' of the development of human ethical practice. According to this history the first ethical norms were launched in the ancient world of the hunters and gatherers and their initial function was to remedy altruism failures. Kitcher wants to show that the emergence of ethical norms can in this case and in general be explained without referring to supernatural causes or philosophical revelation. Furthermore, he claims that the first manifestation of the ethical project still serves as an ideal. In my comment I will contest the plausibility of Kitcher's analytical history and question whether the presumed characteristics of ethics in prehistoric times could still be binding for us today.
\end{abstract}

\section{Standing On the Shoulders of Hunters and Gatherers}

Imagine a group of people facing severe conflicts and cooperation difficulties. They are aware of these problems and rightly reason that they would all do better if these problems could be solved. They know that one tool for solving such problems are norms prescribing certain kinds of behaviour. If the right norms were selected and obeyed, the conflicts and difficulties could be overcome. The members of the group also know that there is no external power, transcendental being or deus ex machina who will provide and enforce these norms and neither is there hope of revelation through which they could recognize which kind of norms would be best. So the members of the group, viewing themselves as the only authoritative source of norm-making and their own welfare as the only available yardstick for evaluative judgments, engage in a deliberative process in which all members of the group are included. In these deliberations they work out how they would prefer to live together, examine different options of norms and their impact as possible remedies for their problems, thereby giving the arguments and interests of all group members equal weight. They are also conscious of the problem of enforcement and think about such devices as punishment and socialization to strengthen the effectiveness of norms. In the end, they reach a consensus and each group member accepts the collective decision as binding and is ready to obey and support the norms which they have agreed on.

\footnotetext{
* As always I thank Margaret Birbeck for patching up my English.
} 
The members of this group obviously manage to cope with a bundle of quite demanding challenges: they are not only able to recognize the deontic meaning of norms and rules and their function as tools for guiding human behaviour, they are also aware that norms can be changed deliberately, chosen with different contents and will have different consequences in the short and long run. Furthermore, they have sufficient insight into the dynamics and mechanisms of their social life and interactions to diagnose some of their problems as outcomes of ill-adapted individual and collective behaviour, while at the same time envisaging improvements to this behaviour by establishing certain norms. However, they are not only capable of implementing and enforcing norms of conduct, they also act according to process norms that regulate how to elaborate on norms of conduct and how to reach conclusive collective decisions on which norms to enact.

This seems to be a picture of a bunch of paradigmatically modern, clearsighted, clever, competent and enlightened people. They are organizing their social life by thoughtfully developing and implementing social norms within the framework of a rather complex process of collective deliberation and decision, honouring far-reaching principles of direct democracy and egalitarianism. They are capable of working out efficient social technologies to better their situation without referring to experts and authorities. The implementation of norms is the result of accomplished social engineering, not merely left to chance and undirected social processes. The whole set-up looks like the fortunate end result of a long historical learning process.

According to Philip Kitcher the opposite is true: what we just have imagined is a situation reaching fifty thousand years back! It pictures our remote ancestors sitting around the campfire, discussing their social problems in the 'cool hours' of the day. Just recently have they acquired the capacity of 'normative guidance' and are able to grasp the meaning of norms and rules as tools to regulate behaviour. And yet, miraculously, they are not only capable of expressing simple orders and commands, but have instantaneously acquired the remarkable ability to recognize the instrumental value of general social norms as a means to organize a whole group and to deliberate conjointly about the norms which would be most suitable to solve the most pressing problems the group faces. Problems which Kitcher claims were rooted in the limitations of the altruistic dispositions of the members of the band and which "the first ethicists" overcame by agreeing consensually on norms which prohibit violence and prescribe the sharing of scant resources: "They imagine possible distributions [...] each considering not only his or her own share but also those of the others, and attempting to recognize the felt consequences for the others. From their reflections and exchanges comes an agreed-on vision of which distributions are preferred." (EP, 104f.) This process marks the invention of ethics and the beginning of the "ethical project". Equality was important around the campfire: "In formulating the code, the voices of all adult members of the band needed to be heard: they participated on equal terms. Moreover, no proposal for regulating conduct could be accepted unless all those in the group were satisfied with it. [...] This form of socially embedded 
normative guidance set the stage for the evolution of the ethical project." ( $E P$, 96f.)

However, as Kitcher emphasizes more than once, his narrative of the invention of ethics is not supposed to be an empirical story how things actually happened but a 'how possibly' story, an 'analytical history' that can demonstrate that things could have evolved in a certain way. Nevertheless, this 'how possibly' story is not only an arbitrary and replaceable anecdote. Quite the contrary, it lays the ground for an adequate understanding of the ethical problems we face even today and can elucidate the epistemic status of ethical theory. Two things seem to be central for Kitcher:

First, a successful 'how possibly' story which shows that ethics can emerge as a social technology, invented and realized by humans as a reaction to the problems and shortcomings they face, proves that ethics can come into existence without "appeals to divine will, to a realm of values, to faculties of ethical perception and 'pure practical reason"' $(E P, 4)$. No transmundane revelation or philosophical discovery is necessary.

Second, an adequate understanding of the beginning of the ethical project and an insight into the initial function of ethical practice is decisive for a solution to our contemporary challenges. We have to understand later functions of ethics "as generated from the solutions previously obtained" $(E P, 7)$. Even more so, over the divide of thousands of years the campfire discussions of our remote ancestors and their results should serve as an enduring role model and we should attempt to renew the original project: "Pragmatic naturalism's proposals are motivated by conceiving the current human situation as analogous to that initially prompting the ethical project. As it was in the beginning, so too now $[\ldots]$ the original function of ethics - to remedy altruism failures - remains primary." (EP, 8f.) Therefore, our present-day ethical ideals should be grounded in an "examination of the ethical project in its original form" and should preserve the "most basic features while stripping away distortions that have since occurred" (Précis, 16). What followed after the golden age of the campfire is in many respects a decline. It is time to remember and return to our roots.

In the following I will discuss these two claims. I agree with the first, but I doubt that we have to go back fifty thousand years and speculate about our forefathers' discussion groups to provide a naturalistic story of how ethical practice is possible without divine command or metaphysical burdens. I do not agree with the second claim and I contest the plausibility of Kitcher's 'how possibly' story. I think we can imagine a different chronology of events that challenge the conclusions drawn by Kitcher. I will speculate about three alternatives regarding, first, the vision of campfire deliberations, second, the assumption that social practice starts by remedying altruism failures, and, third, the harmonious view of the development of large groups. 


\section{Human Action, Not Human Design}

The first thing that can quite obviously trigger skepticism is Kitcher's assumption that our forefathers sat around the campfire in the 'cool hours', deliberatively and prudentially discussing the pros and cons of norms that could remedy their social problems, deciding under an unanimity rule which norms to choose and then proceeding to plan and execute the implementation and enforcement of the agreed-on rules. What Kitcher describes is not a simple operation even if this is insinuated by the picture of people sitting around a campfire. Quite the opposite, this kind of intentional creation of norms seems to be the product of a long development which cumulates eventually in legal rule-making and the positivisation of norms as laws. It presupposes in rudimentary form the acceptance of higher-level, secondary norms, in terms of H. L. A. Hart rules of recognition, rules of change and rules of adjudication - complex structures which are typical of legal systems and would hardly naturally accompany the very first insights into 'normative guidance'. From the capacity to apprehend, express and follow simple commands and orders there seems to be a long way to the cognitive faculty to abstractly understand the function of general social norms and establish a collective norm-making process.

What could be an alternative and more realistic vision? First of all, it should be noted that public deliberation, collective decision-making and intentional planning are not the only forms of social embeddedness. Social embedding of norms does not necessarily presuppose that an "agreed-on code, articulated and endorsed after discussion around the campfire, was transmitted to the young through training regimes that had also been socially elaborated and accepted" $(E P, 96)$. The 'social character' of the emergence and enforcement of norms could also be incorporated in non-intentional, spontaneous social processes. Kitcher mentions himself the danger "to overemphasize the social character of the ethical project" $(E P, 98)$. The alternative is not only a biological theory about the origins of ethics, but a 'thin' conception of social embeddedness that connects the initial materialization of social order still with human action, but not with human design.

How could a 'how possibly' story of such a spontaneous emergence of social norms be told? What kind of mechanism could operate to aggregate separate actions of numerous individuals unintentionally into the existence of an overall social pattern? The first step would be reactive responses of single individuals or a group of individuals toward actions by others whose consequences they do not like. These negative externalities could occur in bilateral interactions affecting individual goods, when violence breaks out or the booty is not shared, they can affect collective goods when members of a group do not engage sufficiently in common enterprises like hunting or gathering, or when cooperation fails simply because of lack of mutual adjustment. The occurrence of such externalities could elicit reactions starting on a continuum from 'soft' expressions of frustration and disappointment, breaking off cooperation and refusing further interaction, up to aggressive retaliation and punishment. These reactions could come from single individuals or a group of people, from persons directly concerned or from 
supporting bystanders. Naturally, the ability of normative guidance will largely improve the options for reactive behaviour in making it possible to express wishes and preferences in regard to the behaviour of others through explicit commands and orders.

We could think of different possibilities how, starting from this kind of reactive behaviour, stable regularities will gradually evolve. If we assume that the social context is constituted by a small number of more or less equal actors who interact with each other in a close-knit community with sharp demarcations, then it is not implausible that a mechanism of reciprocity could be effective which endogenously creates incentives for mutual norm-obedience-not by an execution of a plan, but with the help of an invisible hand that produces a result as if it is the result of a master mind.

Of course, whether the outcome of such a process is indeed guided by an invisible hand and fulfills a certain useful function for the group as a whole- for example stabilizing social harmony — or whether a developmental path begins that leads to sub-optimal results, is not predetermined. Lock-in effects and equilibria with quite different levels of efficiency are possible. Although a process of cultural evolution may become effective which by competition and group selection favors those groups who manage to successfully implement welfare-enhancing social norms.

\section{The Social Project}

Leaving aside here the details of the nuts and bolts of such a gradual evolution of social order: Would this be just another 'how possibly' story of how the initial function of ethical norms happened to be an amelioration of altruism failures? That is not necessarily the case. If actors face externalities resulting from each other's behaviour and solve this problem by mutually enforcing a norm that improves their situation, that need not be equated with a remedy of altruism failures. When a norm is established that regulates situations of conflict and the conflicting parties expect that this norm is generally obeyed, then it may not pay to start a violent conflict and take the risk of being hurt in return. When a norm exists that regulates situations of sharing and general compliance with this norm is also common knowledge, then there may be no incentive to break this rule and endanger one's own share in a future exchange. Under such living-conditions there would be no pressure to develop additional devices of norm enforcement like institutionalized punishment, internalization, conscience or the belief in a divine enforcer. The mechanism of reciprocity will teach the individuals that it is better to comply with these norms than to defect-no special capacities for complicated calculations or foresight are needed here.

The efficacy of social norms in these cases would be a result of conditional norm-compliance: as long as everyone in the group expects that other group members will comply and that breaking norms will be paid back in kind, no one will be motivated to deviate. These norms would be self-enforcing, because conditional norm-compliance can be the most expedient strategy in small groups 
with high transparency and tight social control where the same individuals interact with each other over extended periods.

In such an environment, however, the emergence of norms would not deliver a social technology to overcome a shortage of altruism but to remedy coordination failures. Without the ability of normative guidance and an understanding of norms and rules as instruments to designate a certain class of desirable behaviour, many types of coordination problems could not be solved efficiently. Even if a certain behavioural regularity were in the common interest of individuals, they may not be able to specify this regularity with sufficient clarity and unambiguousness if they lack the means of normative prescription. As soon as people develop an ability to express and obey norms, they have more options to coordinate a mutually advantageous practice.

The crucial problem before the development of the ability for normative guidance would then not have been too little altruism but too few cognitive capacities: the individuals were not able to configure and establish that kind of regular behaviour that would have served their interests best-not beyond the scope and restrictions of their altruistic dispositions but on the basis of these. A norm that defines an equilibrium for coordination does not compensate for missing altruism but helps the actors to promote their given interests.

Admittedly, even in a dense knit group there may be contexts in which deviating from social norms would pay and where these norms cease to be solely solutions to coordination problems. However, it is not implausible to assume that in small bands whose members are more or less permanently in contact with each other over long sequences, these contexts are comparatively rare and do not create pressing problems which demand special solutions.

The emergence of self-enforcing norms which solve coordination problems and evolve as results of spontaneous interactive processes seems better labeled as a social project than as the first instantiation of an ethical project. Conditional norm-compliance that is based on the expectation of an accordant behaviour of the other members of a social group and serves the self-interest of the actors lacks the special commitment and dedication we usually associate with the obedience towards ethical or moral norms.

\section{The Legal Project}

What narrative does Kitcher present for the development of large groups with elaborated institutions and complex systems of cooperation after "the first forty thousand years of the [ethical] project were directed toward the needs of small groups, whose members worked out their social lives on terms of approximate equality" $(E P, 11)$ ? Once again, this development is described as a case of insightful diagnosis of a social predicament and its consensual solution. New possibilities and enlarged expectations "created pressure to increase the supply of basic resources, leading to division of labor, introduction of special roles, differentiation of contributions, and a far more extensive set of aspirations" (Précis, 11). The question for Kitcher is, therefore, "how might the ethical project have 
introduced, tolerated, even favored" divisions by status and role, and the origin of institutions that extend those divisions $(E P, 115)$. And the answer is: the members of the ancient bands eventually recognize the desirability of increased efficiency in acquiring resources, and "because that situation is desirable, there is pressure to institute social arrangements that help achieve it" (Précis, 5).

To facilitate the growth of a social group into a large society, Kitcher rightly states that the initial equality must break down, and division of labor and institutions such as property must develop. Kitcher's 'how possibly' story frames this development as a "stepwise evolution of the ethical project" $(E P, 131)$, as an intentionally designed scheme to construct more complex systems of cooperation and an "obvious strategy for obtaining more of the things everybody needs" $(E P, 122)$. The ethical code is deliberately expanded to regulate collective activity "when a thousand or more people live within the walls of the same city" and "strategies of peacemaking through face-to-face reassurance are no longer applicable" $(E P, 116)$.

What alternative view could be presented that would again challenge the endearing picture of social developments as outcomes of consensual discussions about the ethical project? Kitcher himself refers to "early law codes" as "the clearest indications of the evolution of ethical codes that occurred late in prehistory" $(E P, 118)$. But does the emergence of legal codes indeed signify a linear developmental path from the socially established norms in an egalitarian band to the normative systems that facilitate social order in large societies? Does the law code provide evidence that the laws are still socially embedded in an "ethical project", growing out of "agreed-on" rules? Kitcher claims that "to trace the possible evolution of the ethical project", it "is legitimate to begin with social discussions of regulations for conduct and end with legal codes" $(E P, 120)$. But is it plausible to assume that harmonious growth out of "social discussions" is a probable path for the emergence of the early law systems? Or is it wishful thinking and a projection of the ethical foundations of law systems in modern democracies onto quite different circumstances? The available historical evidence speaks against the first interpretation.

Instead of suggesting an egalitarian social group, slowly growing and consensually figuring out solutions to the new challenges, historical records seem to favor the view that primordial social groups once on the path to growth very soon split into producers and warriors - much in the way Plato already pictured the growth of societies as accompanied by internal division into guardians and normal citizens. A considerably less pleasant 'how possibly' story could be made up that assumes that the warriors, as a relatively small and cohesive group, will form an efficiently functioning unit with the aim of oppressing and exploiting the producers and to seize the bulk of their products. In such a society the problems of cooperation would be solved, on the one hand, by the close-knit structure of the ruling elite which supports spontaneous cooperation and, on the other hand, by systematic repression and punishment of the normal citizens by the 'guardians'. It is conceivable that such a structure would allow a society to grow to a considerable size, develop a high level of division of labor, create differentiated institutional structures and manage to produce a significant and 
increasing surplus. However, there would be no sign of an ethical project, socially embedded in a consensual norm-making process with the aim of securing social harmony and enlarging the scope and intensity of altruism and overall welfare. Instead we can view this sketch as a 'how possibly' story for the emergence of a legal project, implementing authority structures and empowered law-givers as sources of law codes and introducing social control and punishment by specialized societal organs that have superior coercive means at their disposal. Of course, this is not a story about a legal project that conforms to our standards of rule of law and division of power. Thrasymachus who infamously claimed that the principles of justice are instruments in the interest of the strong and mighty would be the right witness here.

Kitcher considers quite a similar alternative to his own 'how possibly' story himself, picturing a dictator who enforces norms of cooperation by means of force and violence. Kitcher denies that this 'fantasy' presents a serious challenge to his approach, since such a dictatorship does not fulfill the original function of ethics "to promote social harmony through the remedying of altruism failures" $(E P, 225)$. This argument is puzzling. Kitcher presents his own 'how possibly' story just to make it plausible that the original function of ethics was to remedy altruism failures. In this case he cannot reject an alternative story because it does not explain this function but develops the hypothesis that social norms and social order can emerge in other ways and with other functions-or even suggests that Kitcher's 'how possibly' story is in fact an 'impossibility' story. Otherwise Kitcher must present independent reasons for the assumption that the original function of social norms was to remedy altruism failures and tell his 'how possibly' story just as a handy illustration. However, if the aim is only to produce some story of how it is thinkable that an ethical practice can develop without divine intervention or philosophical revelation, then it is not necessary to take great pains to go back fifty thousand years and carefully consider the available historical evidence-all sorts of 'how possibly' explanations would do the job. And, of course, when campfire discussions and their outcomes are only fictitious presumptions for illustrative purposes, they will lose their status as binding role models.

\section{The Ethical Project}

If we, in accordance with Kitcher, still take up the challenge of providing a naturalistic explanation of the ethical project and if the so far sketched alternative stories were indeed more plausible than Kitcher's campfire tales: when and how could we imagine that the genuine ethical project may really have started? How could an alternative narrative and 'how possibly' story for the emergence of ethical norms be told?

Instead of locating the emergence of ethical norms in primordial small groups, the hypothesis could be put forward that a real demand for an ethical project does not occur before the dawn of large societies. Not until then will the problems of anonymous defection and fragmentary social control become pressing. As 
social interdependency in large groups is not as dense as in small bands, a lot of 'golden' opportunities for deviant behaviour will arise - and thus social norms will cease to be self-enforcing devices to solve coordination problems but will demand obedience and enforcement in the face of endemic incentives to defect. Therefore the need for additional provisions to enforce norm compliance arises. What has to be achieved from now on is securing unconditional norm-compliance in contrast to mere conditional norm-compliance.

An invisible-hand explanation of the evolvement of psychological dispositions to unconditionally conform to norms could, for example, refer to the advantages people with such a disposition could expect from others who are searching for reliable cooperation-partners. But let us suppose that such dispositions for unconditional norm-compliance may have originated and are sufficiently effective. Can we now finally agree with Kitcher that the primary function of ethical norms, the amelioration of altruism failures, is eventually established? Doubt is possible again. In the assumed situation, social norms which prescribe certain kinds of desirable behaviour are already existent. The new problem that arises is a weakness in the motivation to obey these prescriptions, and weak altruism may be only one possible cause for this. Can it be attributed to weak altruism if a member of a certain group does not obey the norms which are relevant for trading with strangers? Is it due to altruism failure if a citizen fails to participate in the joint activities to build a defense wall around a city? And is it an altruism failure if a father unduly cares about the welfare of his children or family and thereby neglects his duties as a member of his larger social group? It seems to be more fitting to classify these and other examples of disregarding existing social norms as weaknesses of commitment, while being aware that different kinds of motives and incentives may be relevant as causes for these weaknesses. Therefore, from this point of view the initial function of the ethical project would have been to remedy not altruism failures but commitment failures - which then may have led to the evolution of such institutions as education and socialization and such concepts as duty or categorical norm-compliance.

\section{Should We Really Take Our Ancestors Seriously?}

I am not insisting that my alternative stories are really better. Maybe new anthropological and archeological findings and new developments in the theory of evolution support Kitcher's 'how possibly' story, maybe all stories so far are wrong and we have to rewrite them in substantive ways. Maybe the ethical project as an effective social practice started only five hundred and not fifty thousand years ago - everything else before was just cheap thoughts in the ivory tower of some imaginative thinkers who were detached from everyday social life.

Would this really matter? As Kitcher himself asks: "How can any history, however carefully focused and articulated, bear on philosophical questions about ethics?" (EP, 6) Naturally, it would matter for anthropology, sociology and the history of ethics which from their different angles want to understand and explain how social norms and ethical practice might have evolved in former times. 
However, do the characteristics of human ethical practice early in history really "bind those who come later" $(E P, 229)$ and matter for normative ethics and social practice today? If it turned out to be an illusion that our ancestors tried to remedy altruism failures while sitting around the campfire would our options change to ethically solve pressing issues like joint action on a global scale to prevent climate change, to overcome the divide between the poor and the rich or to come to morally acceptable treatment of the problems of euthanasia, abortion or stem-cell research? Or, in the opposite case, if they really did do that, would it be wise for us today to take their example as an authoritative role model?

Kitcher has a clear standpoint. As an essential part of his "normative stance" he proposes a "renewed emphasis on the original function" of ethical norms. Because "the prevalence of altruism-failure is even more extensive (and potentially dangerous)" now, "we should scale up the original approach to the ethical project" (Précis, 15f.). New perspectives and possibilities for our conceptions of a worthwhile life need to be integrated with the focus on altruism failure and we should not "be so beguiled by the idea of developing those possibilities and desires that we neglect the original problem, and fail to discharge the original function on a much-enlarged-global-scale" (Précis, 18). This applies not only to substantive issues but also to matters of procedure: "Similarly, in considering ethical method, my normative stance seeks to emulate the early stages of the ethical project. It envisages an ideal conversation as one in which all group members - that is, all human beings, including those who will come after us - are included." (Précis, 16)

The contraposition would claim that it does not matter at all for our ethical problems today if fifty thousand years ago the ethical project was invented or not. If the original function of ethics was indeed to overcome altruism failures, it does not commit us to still accept this function as obligatory and fundamental, and if there was egalitarian discussion and deliberation about ethical questions, it does not commit us either to accept the same method. A golden age of the campfire should bother us today as little as a dark age of the hatchet.

If Kitcher is in fact right in his diagnosis that today the "prevalence of altruism-failure is even more extensive (and potentially dangerous)" than in former times, why is this insight not sufficient to argue for remedies of this failure? And why should the fact that altruism failures played a disruptive role already fifty thousand years ago add any weight to the argument? Or, to put it the other way round, if the proposed 'how possibly' story about the initial function had to be discarded, why should this weaken the need to remedy altruism failures today if they have been identified as a core problem?

The same applies to questions about the appropriate ethical method. If deliberation and consensus are indeed convincing ideals, we may be well advised not to make their value dependent on the assumption that this was how it all started. We should rather develop independent arguments for these concepts. I believe that my skeptical remarks on the plausibility of campfire discussions between our remote forefathers are well-founded and that a spontaneous emergence of social norms is much more probable. But should this prevent us in any way from preferring 'deliberative norm-making' to cope with the ethical prob- 
lems we face today? And even if there was a golden age of campfire-democracy: this would not exempt us from finding arguments which have their own validity to advocate 'standards of ideal conversation' and 'mutual engagement' under prevailing conditions and restrictions. And, in fact, this is exactly what Kitcher himself is doings on many pages.

Kitcher's main argument for the "enduring importance" of the initial function of ethics seems to be that this is the only way "to achieve an important form of coherence" (Précis, 9). In this spirit Kitcher praises the "normative stance" he proposes as having the decisive advantage that it "is coherent and that rivals that downplay the original function of ethics are not" (Précis, 18). Any alternative approach that lacks this requirement "encounters severe difficulties. Not only is it unclear what method of ethical discussion it can offer, or how method and conception of the good can be coherently developed, but there is significant danger that the alternative will presuppose the function it is supposed to transcend." (EP, 367f.)

But what genuine advantage can be gained by indeed being able to trace back the functions of ethics today in an uninterrupted chain to ancient times, and what is the loss if not? Has coherence in our social practice and development intrinsic value of its own? Even under the aspect of feasibility the relevance of coherence seems to be disputable: the fact that something was possible or not in the small band of hunters and gatherers reveals hardly anything about the possibility or impossibility today. There might be some serious path dependency in ethical developments and we can agree with Kitcher that the ethical project is a product of history, that "we, collectively, made it up, and have developed, refined, and distorted it, generation by generation" $(E P, 2)$. But the fact that ethics "emerges as a human phenomenon, permanently unfinished" does not shackle us to the ethical projects in the remote past and does not commit us to the developmental path these projects have taken up to now. Certainly, it is an interesting and important question for a naturalistic approach to ethics and also from the perspective of descriptive and explanatory disciplines how social, legal and moral norms have emerged as societal facts and what brought about the empirical conditions of their effectivity and durability. And it is also true that the answer to this question bears significance for normative ethics, because normative ethics has to take the factual constraints into account which are relevant for the empirical existence of moral norms. However, even if conditions and restrictions which are the result of a practice in the past have to be taken into consideration, they hardly reach back to the hunters and gatherers. We may not be able to radically change the ethical practice of a society from one generation to the next. Coherence plays its role as a constraining condition. Nevertheless, it is hardly evident that coherence over thousands of years is still "forming the bases of the ways in which people today regulate their conduct" $(E P, 3)$. Furthermore, it seems to be at least an open question whether the perspective that "the range of alternatives for continuing the ethical project is greatly narrowed" once "remedying altruism failures and mutual agreement are taken seriously" $(E P, 368)$ is more a promise or a threat. 
One last remark: We can still share Kitcher's aim to liberate discussions on ethics from a sense of mystery and to show in line with a naturalistic approach that the emergence and durability of ethical practice is possible without reference to a divine will or a realm of objective values. We can also agree with him that "to answer skeptics claiming that 'real ethics' requires resources naturalists cannot allow, some narrative needs to be given" ( $E P, 12)$. So, how could we advance explanatory hypotheses about how ethical practice can occur if not in the way Kitcher has tried? Well, we can make our life a bit easier. We do not have to speculate on developments fifty thousand years ago. We can start today! Sociological and psychological theories of socialization and norm-internalization, pedagogical theories of education and character building, empirical evidence from experimental studies and field research, game and decision theory, and yes, of course, evolutionary theory and history, they all contribute to identify and understand the empirical conditions and mechanisms by which the ethical project can develop and be effective. This research can to a large extent focus on the actual living conditions and the cognitive capacities and emotional dispositions people have today. If we want to know the right thing to do and how we can help to bring it about, we need not look back too far into the past to get a decent answer.

\section{Bibliography}

Kitcher, P. (2011), The Ethical Project, Cambridge/MA-London

-, Précis of The Ethical Project, in: Analyse $\&$ Kritik 34, this issue, 1-19 